\title{
Minimally invasive Columbus egg
}

\author{
Gabriele Di Giammarco, MD, and Daniele Marinelli, MD
}

\author{
From the Cardiac Surgery Department, Universita degli Studi Gabriele d'Annunzio Chieti e Pescara, Chieti, Italy. \\ Disclosures: Authors have nothing to disclose with regard to commercial support. \\ Received for publication Aug 9, 2017; accepted for publication Aug 18, 2017; available ahead of print Sept 15 , \\ 2017. \\ Address for reprints: Gabriele Di Giammarco, MD, Chief of Cardiac Surgery Department, Universita degli Studi \\ Gabriele d'Annunzio Chieti e Pescara, Via dei Vestini, 66100 Chieti, Italy (E-mail: gabrieledigiammarco57@ \\ gmail.com). \\ J Thorac Cardiovasc Surg 2018; 155:e45 \\ $0022-5223 / \$ 36.00$ \\ Copyright (C) 2017 by The American Association for Thoracic Surgery \\ http://dx.doi.org/10.1016/j.jtcvs.2017.08.041
}

In the article by Ando and colleagues ${ }^{1}$ published on this issue of the Journal, there is an emblematic experience on the management of right ventricular failure in patients with left ventricular assist devices (LVADs). This complication has a prevalence varying from $9 \%$ to $40 \%{ }^{1,2}$ and is characterized by fairly high mortality in the vast majority of cases. When it is not adequately and timely treated, it is responsible for the development of a multiorgan dysfunction syndrome with repercussions for transplant candidacy and for the outcome of a possible heart transplant. In addition, the development of a right ventricular insufficiency results in a prolonged hospital stay, with increased social costs and increased discomfort for patients and their families.

The technique proposed by Ando and colleagues ${ }^{1}$ came after a series of solution attempts that were unsuccessful for the development of uncommon complications related to therapeutic choices. The previous LVAD implantation through a full sternotomy undoubtedly made a reentry through the same surgical access riskier for many reasons. A failing, dilated right ventricle, adherent to the posterior sternal surface, was at risk for rupture during reentry maneuvers, as was the LVAD outflow conduit running behind the sternum. It is of particular interest that the retrograde cannulation of the right atrium was performed through the tricuspid valve with the Seldinger technique led by fluoroscopy. Concerning this issue, the option of transesophageal echocardiographically guided cannulation could in our opinion be further upgrade the method. This technical solution to right ventricular assist device implantation has allowed restoration of organ function and stabilization of the clinical situation, mobilizing the patient and giving him the chance to reach the heart transplant.

In the era of minimally invasive LVAD implantation, the proposed solution is extremely beneficial because it is not likely to frustrate the intention to preserve sternotomy for transplantation. In addition, the clinical stabilization of

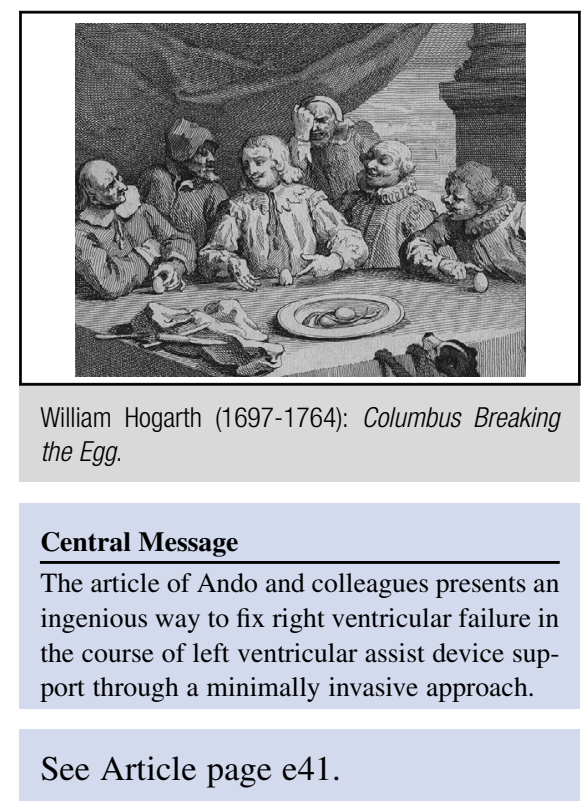

the patient helps to avoid the use of inotropes, with obvious benefits for organ function preservation. Finally, the expectation for a new heart in a condition of hemodynamic stability is an important opportunity for a better allocation of available organs.

According to an apocryphal but illustrative tale, in 1493, after returning from the trip to the alleged Indies, Cristoforo Colombo was invited to dinner by Cardinal Mendoza. During dinner, he was told that anyone could do what he had done. Then he challenged the diners to make an egg stand up straight on the table. After several unsuccessful attempts Colombo offered the solution: breaking one of the poles of the egg that became the base of its support. The diners protested that everyone could get that result. Colombo replied that everyone could have but that he had done so. We therefore believe that the Ando and colleagues ${ }^{1}$ are to be congratulated for the simplicity and the perspective of reproducibility of the proposed solution.

\section{References}

1. Ando M, Hiroo T, Naka Y, Takeda K. A minimally invasive right ventricular assist device insertion late after a continuous-flow left ventricular assist device implantation. J Thorac Cardiovasc Surg. 2018;155:e41-3.

2. Houston BA, Kalathiya RJ, Hsu S, Loungani R, Davis ME, Coffin ST, et al. Righ ventricular afterload sensitivity dramatically increases after left ventricular assist device implantation: a multi-center hemodynamic analysis. J Heart Lung Transplant. 2016;35:868-76. 